\title{
Grafting of Tetrahydrophthalic and Maleic Anhydride Onto Polyolefins in Solution
}

\author{
Paulo G. S. Campos $^{a}$, Márcia C. A. Fantini ${ }^{b}$ and Denise F. S. Petri ${ }^{* a}$ \\ ${ }^{a}$ Instituto de Química, Universidade de São Paulo, Av. Professor Lineu Prestes, 748, and ${ }^{b}$ Instituto de Física, \\ Universidade de São Paulo, Rua do Matão, Travessa R, 187, 05508-900 São Paulo - SP, Brazil
}

\begin{abstract}
Polietileno de baixa densidade (LLDPE) com comonômeros 1-buteno e 1-octeno foram funcionalizados com anidrido tetrahidroftálico (THA) e anidrido maléico (MA) em solução na presença de peróxido de benzoíla (BPO), de acordo com planejamentos fatoriais. As variáveis testadas foram concentração de anidrido, concentração de peróxido, tempo de reação e tipo de comonômero. As formulações foram analisadas por espectroscopia vibracional no infravermelho FTIR. Na funcionalização com THA o efeito principal tempo de reação foi significativo, assim como, a interação deste com a concentração de THA, enquanto que no caso do MA as concentrações de BPO e MA foram significativas. Poliolefinas modificadas com teores semelhantes de THA e MA foram analisadas por calorimetria exploratória diferencial (DSC) e por difração de raios X (XRD). Amostras modificadas com THA e MA apresentaram redução na temperatura de fusão de $4,3{ }^{\circ} \mathrm{C}$ e $1,4{ }^{\circ} \mathrm{C}$, respectivamente, com relação ao polímero original. Alterações devido à funcionalização também foram evidenciadas por forte redução nas áreas dos picos de difração relativos aos planos cristalinos (110) e (200), corroborando com os dados de calorimetria exploratória diferencial (DSC).
\end{abstract}

Tetrahydrophthalic (THA) and maleic (MA) anhydrides were grafted onto linear low density polyethylene with comonomer 1-butene and 1-octene (LLDPE) in solution in the presence of benzoyl peroxide (BPO) following experimental designs, where anhydride and BPO concentrations, type of comonomer and reaction time were varied. The formulations were analyzed by Fourier transform infrared spectroscopy (FTIR). In the case of THA modified polyolefins, the time of reaction and the interaction between time of reaction and THA concentration influenced the process, whereas the MA and BPO concentrations influenced the grafting of MA onto polyolefins. THA and MA modified polyolefin samples with similar grafting contents were analized by differential scanning calorimetry (DSC) and X-ray diffraction (XRD). THA and MA functionalized polyolefins presented reduction in the melting temperature of $4.3{ }^{\circ} \mathrm{C}$ and $1.4{ }^{\circ} \mathrm{C}$, respectively, comparing with the original polymer. These effects corroborate with the strong reduction in the areas of the diffraction peaks (110) and (200) after the grafting process.

Keywords: polyethylene, anhydride, experimental design, X-ray diffraction, differential scanning calorimetry

\section{Introduction}

The modification of polymers by grafting reactions with maleic anhydride (MA) is a subject of large technological and scientific interest. Just this year to date 128 patents and 369 scientific reports have been published ${ }^{1}$ on this subject. Polymers, in particular, polyolefins are inert materials. ${ }^{2}$ Grafting polar functional groups like MA on the polymer chains improves their adhesion to other polymers or substrates. One of the most common methods to achieve the polyolefin modification with MA is the reactive process in the presence of a peroxide. ${ }^{3-17} \mathrm{~A}$

\footnotetext{
* e-mail: dfsp@iq.usp.br
}

comprehensive review of the free radical reactions mechanism involved in this process was published by Moad. ${ }^{16}$ The main advantage of such reactive process are the absence of solvent, the short reaction time and it is a continuous process. However, besides the main reaction, degradation and crosslinking are the most often cited side reactions in the reactive process.

An alternative to the reactive process is the polymer modification in solution. ${ }^{15,18-20}$ This method provides little or no crosslinking and no thermal degradation, providing appropriated conditions for the study about the structural effects of the original polymer or the reactants on the grafting reactions. The main disadvantages are the large amount of residual solvent and long reaction time. 
Machado and co-workers ${ }^{15}$ showed that in a series of polyolefins with different ethene/propene the MA graft content increases until $50 \mathrm{wt} \%$ of propene, for higher propene contents crosslinking and degradation reactions are favored, regardless the grafting process. Maurano and co-workers ${ }^{18}$ also observed that keeping MA concentration constant at $20 \mathrm{wt} \%$ the graft content increased with increasing the comonomer content, but it decreased with the comonomer length. NMR studies ${ }^{19}$ evidenced that MA attaches to polyolefin chains in the form of single succinic anhydride as well as short oligomers.

In this work, functionalization reactions of maleic and tetrahydrophthalic (THA) anhydrides onto linear low density polyethylene with comonomer 1-butene and 1octene in solution are investigated. These polyolefins are mainly used in the packing industry. The main questions raised here are the influence of comonomer length, anhydride size and reactivity, amount of initiator and time of reaction on the functionalization efficiency. Although THA is more reactive than MA, it is seldom used in functionalization process. Concerning THA application in chemical process only 11 patents and 22 articles have been published during the last five years. ${ }^{1}$ These figures strongly motivated the present study.

\section{Materials and Methods}

Linear low density poly(ethylene - co-butene) (LLDPEBUT) and linear low density poly(ethylene - co-octene) (LLDPE-OCT) copolymers were kindly supplied by Politeno (Brazil). Their melt indices amount to $0.75 \mathrm{~g} / 10$ $\mathrm{min}$ and $2.50 \mathrm{~g} / 10 \mathrm{~min}$, respectively. The comonomer content amounts to $10 \mathrm{wt} \%$. Benzoyl peroxide (BPO, $\mathrm{M}=242.23 \mathrm{~g} / \mathrm{mol}$ ), maleic anhydride (MA, $\mathrm{M}=98.06$ $\mathrm{g} / \mathrm{mol}$ ) and tetrahydrophthalic anhydride (THA, M = $152.12 \mathrm{~g} / \mathrm{mol}$ ) were purchased from Vetec, Brazil, and used without further purification. Xylene, toluene and acetone were used in the samples dissolution and purification. The chemical structures of reactants are shown in Figure 1.

\section{Functionalization reactions}

Samples of LLDPE-BUT or LLDPE-OCT were functionalized in xylene at $93 \pm 5{ }^{\circ} \mathrm{C}$ under nitrogen atmosphere. The addition of BPO and anhydride was simultaneous. To verify the effect of the process variables on the functionalization efficiency and to obtain response surface plots capable of describing the behavior in the experimental region, the experiments were performed according to experimental designs, where the anhydride concentration, BPO concentration, reaction time and type of comonomer were varied. The experiments were initially performed in duplicate at random following the experimental design $2_{\mathrm{IV}}{ }^{4-1}$, as shown in Table 1. The statistical analysis was performed by means of the software Statistic Plus.

Table 1. Experimental design $2_{\mathrm{IV}}{ }^{4-1}$. The tests were prepared in duplicate $(\mathrm{a}, \mathrm{b})$ and carried out at random

\begin{tabular}{|c|c|c|c|c|}
\hline Run & $\begin{array}{l}\text { Type of } \\
\text { comonomer }\end{array}$ & $\begin{array}{c}\text { BPO } \\
\text { concentration } \\
(\mathrm{g} / \mathrm{L})\end{array}$ & $\begin{array}{c}\text { Anhydride } \\
\text { concentration } \\
(\mathrm{g} / \mathrm{L})\end{array}$ & $\mathrm{t}(\mathrm{h})$ \\
\hline $\begin{array}{l}1 \mathrm{a} \\
1 \mathrm{~b}\end{array}$ & Butene & 2.0 & 8.0 & 2 \\
\hline $\begin{array}{l}2 \mathrm{a} \\
2 \mathrm{~b}\end{array}$ & Butene & 2.0 & 32.0 & 4 \\
\hline $\begin{array}{l}3 \mathrm{a} \\
3 \mathrm{~b}\end{array}$ & Butene & 8.0 & 8.0 & 4 \\
\hline $\begin{array}{l}4 \mathrm{a} \\
4 \mathrm{~b}\end{array}$ & Butene & 8.0 & 32.0 & 2 \\
\hline $\begin{array}{l}5 \mathrm{a} \\
5 \mathrm{~b}\end{array}$ & Octene & 2.0 & 8.0 & 4 \\
\hline $\begin{array}{l}6 \mathrm{a} \\
6 \mathrm{~b}\end{array}$ & Octene & 2.0 & 32.0 & 2 \\
\hline $\begin{array}{l}7 \mathrm{a} \\
7 \mathrm{~b}\end{array}$ & Octene & 8.0 & 8.0 & 2 \\
\hline $\begin{array}{l}8 \mathrm{a} \\
8 \mathrm{~b}\end{array}$ & Octene & 8.0 & 32.0 & 4 \\
\hline
\end{tabular}

Prior to the characterization, the samples were purified by precipitating the hot polymer solution in acetone at room temperature. The precipitated samples were filtered in paper filter and dried in the air. In order to remove the non-reacted initiator, non-reacted anhydride and oligomers, the precipitate was rinsed in acetone in a Soxhlet extractor during $18 \mathrm{~h}$. The samples were dried in vacuum at $100{ }^{\circ} \mathrm{C}$ during $24 \mathrm{~h}$ prior to the characterization.

\section{FTIR spectroscopy}

The degree of functionalization (DF) of all samples prepared with basis on the experimental design (Table 1) was estimated from:

$$
\mathrm{DF}=\frac{\mathrm{h}_{1784}+\mathrm{h}_{1710}}{\mathrm{~h}_{1460}}
$$

where $h_{1784}$ and $h_{1710}$ correspond to the height of the characteristic bands of carbonyl groups (asymmetric $\mathrm{C}=\mathrm{O}$ stretch) at $1784 \mathrm{~cm}^{-1}$ and $1710 \mathrm{~cm}^{-1}$, respectively, and $\mathrm{h}_{1460}$ corresponds to the height of the characteristic band of $\mathrm{CH}_{2}$ (scissoring) at $1460 \mathrm{~cm}^{-1}$, which is proportional to the amount of polyolefin. The DF values are relative and should indicate which variable favors the insertion of anhydrides in the polyolefin chains within the present 
experimental design. Figure 1 presents typical spectra of original LLDPE-BUT, MA and THA functionalized LLDPE-BUT samples.
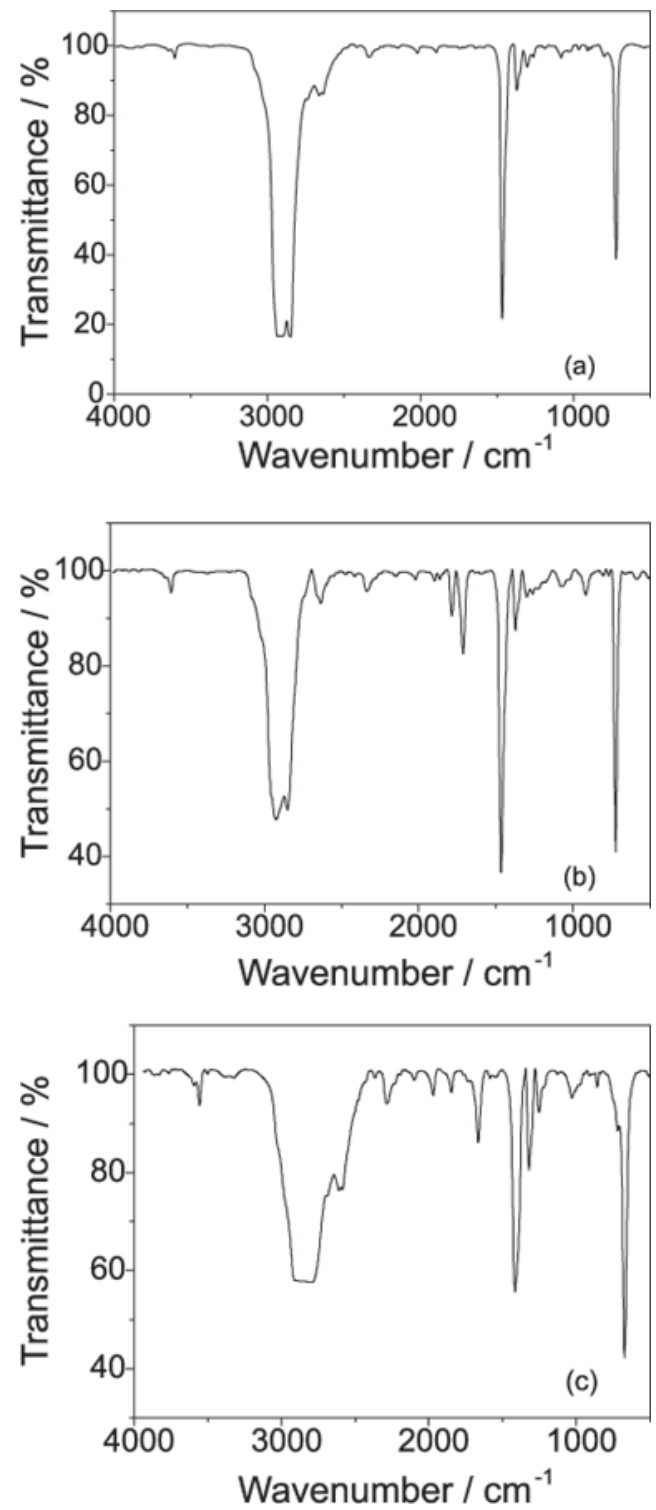

Figure 1. Typical infrared spectra obtained for (a) LLDPE-BUT, (b) MA functionalized LLDPE-BUT and (c) THA functionalized LLDPE-BUT.

Films were prepared by casting hot polymer solutions in toluene at the concentration of $10.0 \mathrm{~g} / \mathrm{L}$. Fourier transform infrared spectra were obtained in a Bomem ${ }^{\odot}$ MB100 equipment with the resolution of $4 \mathrm{~cm}^{-1}$ and 128 scans per spectrum.

X-ray diffractometry (XRD) experiments were performed in a Rigaku diffractometer, Bragg-Brentano geometry, using monochromatized $\mathrm{CuK}_{\alpha}$ radiation $(\lambda=$ $0.154 \mathrm{~nm}$ ), at $40 \mathrm{kV}$ and $20 \mathrm{~mA}$. Wide angle X-ray intensities were collected from $2 \mathrm{q}$ range of $10^{\circ}$ and $50^{\circ}$ with step scanning mode of $0.05^{\circ}$ and time intervals of $10 \mathrm{~s}$. The samples were around $0.5 \mathrm{~mm}$ thick films, prepared by casting on glass slides. The films were previously annealed at $120{ }^{\circ} \mathrm{C}$ under vacuum overnight.

Differential scanning calorimetry (DSC) measurements were performed in a M822 Mettler-Toledo equipment. Two runs were performed for each sample in closed $\mathrm{Al}$ vials, heating and cooling at rate of $10{ }^{\circ} \mathrm{C} / \mathrm{min}$. The amount of material varied from 6.0 to $7.5 \mathrm{mg}$. The melt temperature $\mathrm{T}_{\mathrm{m}}$ was determined from the DSC curve of the second run. All DSC curves are available as supplementary material.

\section{Results and Discussion}

The functionalization of polyolefins in solution in the presence of BPO (initiator) and anhydride might yield several different products. A general scheme for the most probable reactions is depicted in Figure 2, which considers THA as anhydride. Similar reactions are also expected for MA grafting. The thermal homolysis of BPO (Figure 2a) leads to the formation of the first radicals in the solution $(\mathrm{I} \bullet$ ). These radicals abstract $\mathrm{H}$ mainly from the tertiary carbons of polyolefins, ${ }^{19}$ yielding macroradicals in solution, but they also abstract $\mathrm{H}$ from anhydride and solvent molecules. The reaction between macroradicals and radical anhydride is the desired reaction (Figure $2 \mathrm{~b}$ ). The homopolymerization of grafted anhydride molecules on the polyolefins might also take place. ${ }^{19}$ The undesired reactions are the crosslinking resulting from the reaction between two macroradicals (Figure 2c), the homopolymerization of anhydride (Figure 2d) and the insertion of solvent molecules in the polymeric chain (Figure 2e). Disproportioning and $\beta$ scission are possible reactions, but less frequent in polyethylene, they are often observed in polypropylene grafting reactions. In the present study the THA or MA grafting on polyolefins is evidenced by FTIR spectroscopy, while crosslinking and homopolymerization reactions are detected by gravimetric analysis of gel formation and fractionation.

The mean values of DF obtained from FTIR spectra for the THA and MA functionalized polyolefins are shown in Table 2 and 3 , respectively. The functionalization reactions followed the experimental design presented in Table 1. The variance $\left(\mathrm{s}^{2}\right)$ associated with duplicate determinations was calculated from references 21 and 22. The square root of this quantity yields the standard deviation estimate of duplicate measurements. A pooled variance, $\mathrm{s}_{\mathrm{p}}{ }^{2}$, is calculated taking the average of the duplicated variances. The square root of this variance is the most precise estimate of experimental error for the results of the design.

Four principal effects are considered in the experimental design: type of comonomer (A), content of BPO (B), content 
a)

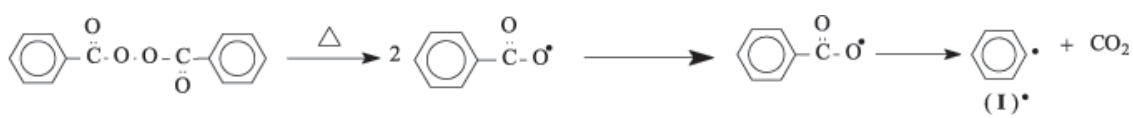

b)

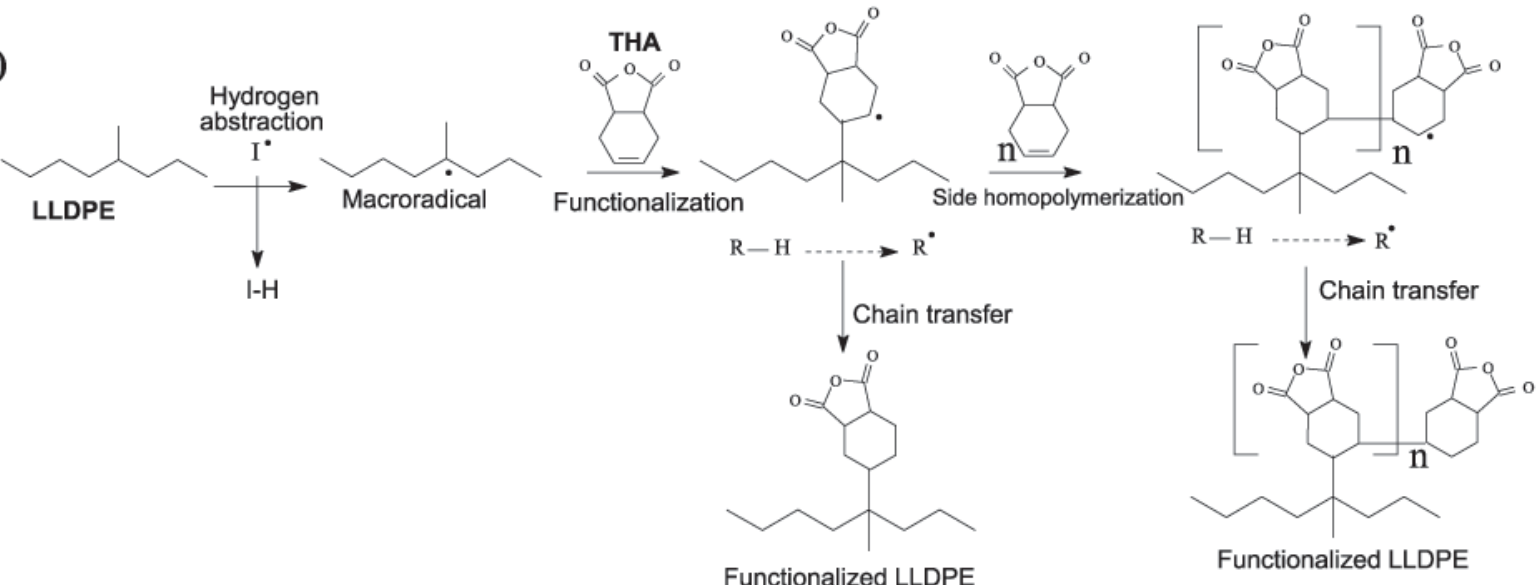

c)

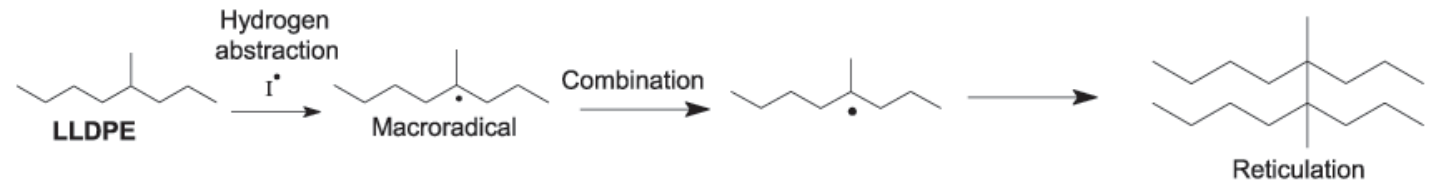

d)

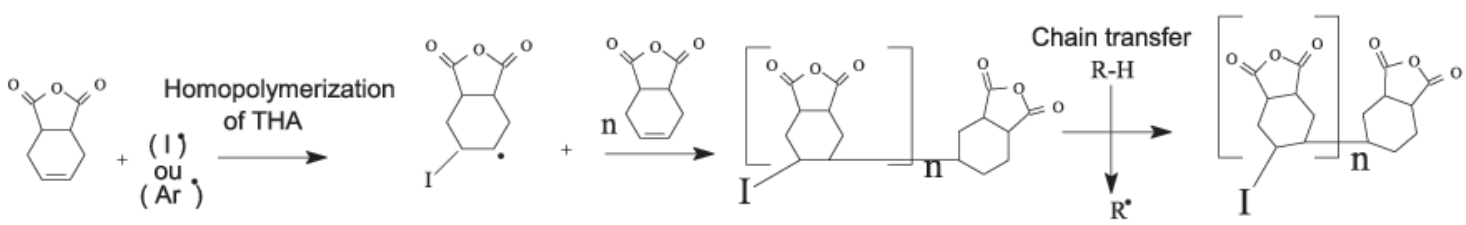

e)

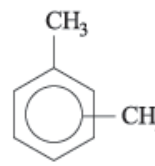

(Ar-H)

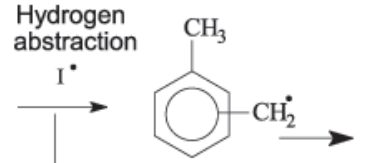

$\underset{\mathrm{I}-\mathrm{H}}{\downarrow} \quad(\mathrm{Ar})^{\circ}$
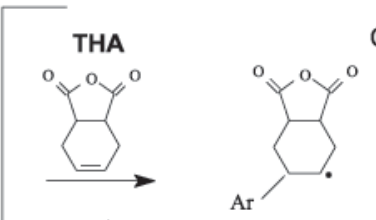
Chain Transfer
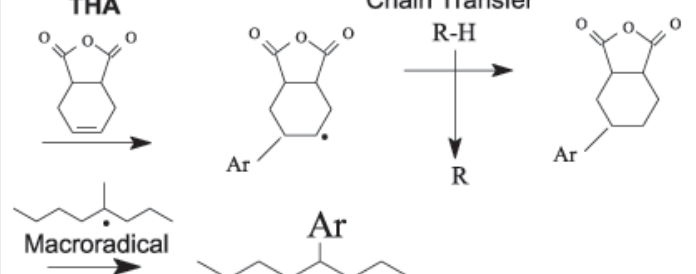

$\mathrm{Ar}$

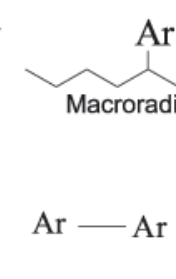

\section{$(\mathrm{Ar})$}

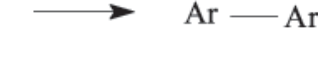

f)

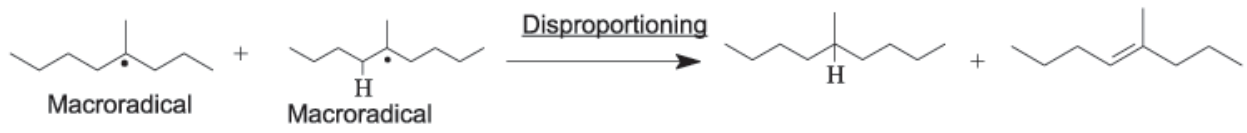

g)

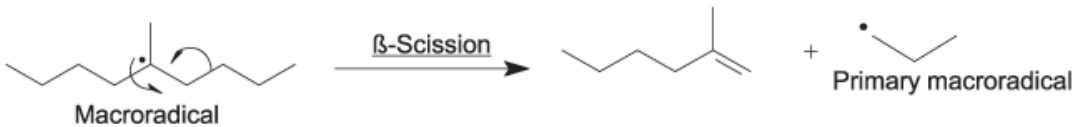

Figure 2. Schematic representation of free radicals formed and the possible reactions (details in the text). 
Table 2. DF and the corresponding variance $\left(\mathrm{s}^{2}\right)$ values obtained for the samples functionalized with THA following the experimental design $2_{\mathrm{IV}}^{4-1}$ (Table 1 )

\begin{tabular}{cccc}
\hline Run & DF & $\overline{\mathrm{DF}}$ & $\mathrm{s}^{2}$ \\
\hline $1 \mathrm{a}$ & 0.36 & 0.39 & 0.0012 \\
$1 \mathrm{~b}$ & 0.41 & & \\
$2 \mathrm{a}$ & 0.34 & 0.46 & 0.0265 \\
$2 \mathrm{~b}$ & 0.57 & & \\
$3 \mathrm{a}$ & 0.36 & 0.29 & 0.0113 \\
$3 \mathrm{~b}$ & 0.21 & & \\
$4 \mathrm{a}$ & 0.08 & 0.09 & 0.0001 \\
$4 \mathrm{~b}$ & 0.09 & & \\
$5 \mathrm{a}$ & 0.40 & 0.52 & 0.0288 \\
$5 \mathrm{~b}$ & 0.64 & & \\
$6 \mathrm{a}$ & 0.10 & 0.09 & 0.0005 \\
$6 \mathrm{~b}$ & 0.07 & & \\
$7 \mathrm{a}$ & 0.32 & 0.27 & 0.005 \\
$7 \mathrm{~b}$ & 0.22 & & \\
$8 \mathrm{a}$ & 0.36 & 0.41 & \\
$8 \mathrm{~b}$ & 0.46 & & \\
\hline
\end{tabular}

Table 3. DF and the corresponding variance $\left(\mathrm{s}^{2}\right)$ values obtained for the samples functionalized with MA following the experimental design $2_{\mathrm{IV}}^{4-1}$ (Table 1 )

\begin{tabular}{cccc}
\hline Run & DF & $\overline{\mathrm{DF}}$ & $\mathrm{s}^{2}$ \\
\hline $1 \mathrm{a}$ & 0.97 & 0.98 & 0.0002 \\
$1 \mathrm{~b}$ & 0.99 & & \\
$2 \mathrm{a}$ & 1.25 & 1.245 & 0.00005 \\
$2 \mathrm{~b}$ & 1.24 & & \\
$3 \mathrm{a}$ & 1.08 & 1.165 & 0.01445 \\
$3 \mathrm{~b}$ & 1.25 & & \\
$4 \mathrm{a}$ & 1.50 & 1.45 & 0.005 \\
$4 \mathrm{~b}$ & 1.40 & & \\
$5 \mathrm{a}$ & 0.92 & 1.00 & 0.0128 \\
$5 \mathrm{~b}$ & 1.08 & & \\
$6 \mathrm{a}$ & 1.26 & 1.24 & 0.0008 \\
$6 \mathrm{~b}$ & 1.22 & & \\
$7 \mathrm{a}$ & 1.16 & 1.11 & 0.005 \\
$7 \mathrm{~b}$ & 1.06 & & \\
$8 \mathrm{a}$ & 1.49 & 1.44 & \\
$8 \mathrm{~b}$ & 1.39 & & \\
\hline
\end{tabular}

of anhydride (C) and reaction time (D). The principal effect of a factor is defined as the difference between the mean response values at the maximum and at minimum levels of that factor. In other words, it is the average of the effects of one factor at all possible combinations of levels of the other factors. Interaction effects are averages of the combined effects of different factors and measure possible synergic and antagonistic interactions between factors. Since the design is fractional the two level interaction effects are confounded. For the present design, the interaction $\mathrm{BC}(=\mathrm{AD})$, the interaction $\mathrm{BD}(=\mathrm{AC})$ and the interaction $\mathrm{CD}(=\mathrm{AB})$ were estimated. Because the experiments were performed in random order the variance of each effect V(ef) is calculated assuming that the experimental errors are not correlated. $\mathrm{V}(\mathrm{ef})$ can be estimated from:

$\mathrm{V}(\mathrm{ef})=\mathrm{s}_{\mathrm{p}}{ }^{2} / 4$

The square root of this variance, $\mathrm{s}_{\mathrm{p}} / 2$, is the standard error of the effect. In the case of THA functionalized samples the standard deviation calculated for the effects amounted to 0.0495 . Multiplying this figure by the tStudent value with 8 degrees of freedom and $95 \%$ of confidence yields 0.114 . It means that effects are statistically significant only if they have absolute magnitudes larger than 0.114 . The estimated effects with the corresponding variance for THA are shown in Table 4. Therefore, only the reaction time (D) and the interaction (CD) between THA concentration and reaction time are statistically significant. Based on these results, a central $2^{2}$ composite design with the variable's concentration of THA and reaction time was performed in quadruplicate (Table 5). Considering tStudent factor with 13 degrees of freedom and $95 \%$ of confidence, only effects with values higher than 0.116 are statistically significant. The effect values shown in Table 6 confirm that the time of reaction and the interaction

Table 4. Estimated effect with the corresponding standard deviation for the THA functionalized polyolefins. Experimental design $2_{\mathrm{IV}}{ }^{4-1}$ (Table 1)

$\begin{array}{lr}\text { Mean value } & 0.3119 \pm 0.02428 \\ \text { A (type of comonomer) } & 0.0187 \pm 0.04945 \\ \text { B (content of BPO) } & -0.09875 \pm 0.04945 \\ \text { C (content of anhydride) } & -0.10625 \pm 0.04945 \\ \text { D (reaction time) } & \mathbf{0 . 2 1 1 2 5} \pm \mathbf{0 . 0 4 9 4 5} \\ \text { BC }=\text { AD } & 0.07625 \pm 0.04945 \\ \text { BD }=\text { AC } & -0.04125 \pm 0.04945 \\ \text { CD }=\text { AB } & \mathbf{0 . 1 3 6 2 5} \pm \mathbf{0 . 0 4 9 4 5}\end{array}$

The lines in bold emphasize the effects that are statistically significant.

Table 5. Central composite design $2^{2}$ and data for THA functionalized samples

\begin{tabular}{lcccc}
\hline Run & $\begin{array}{c}\text { THA } \\
\text { concentration } \\
(\mathrm{g} / \mathrm{L})\end{array}$ & $\mathrm{t}(\mathrm{h})$ & $\overline{\mathrm{DF}}$ & $\mathrm{s}^{2}$ \\
\hline $1 \mathrm{a}-1 \mathrm{~d}$ & 8 & 2 & 0.33 & 0.0065 \\
$2 \mathrm{a}-2 \mathrm{~d}$ & 32 & 4 & 0.43 & 0.0112 \\
$3 \mathrm{a}-3 \mathrm{~d}$ & 8 & 4 & 0.40 & 0.0318 \\
$4 \mathrm{a}-4 \mathrm{~d}$ & 32 & 2 & 0.09 & 0.0002 \\
Central & 0 & 0 & 0.27 & 0.00005 \\
\hline
\end{tabular}

Table 6. Estimated effect with the corresponding standard deviation for the THA functionalized polyolefins. Central composite design $2^{2}$

\begin{tabular}{lr}
\hline Mean value & $0.30667 \pm 0.0252$ \\
B ( THA concentration) & $-0.10625 \pm 0.0535$ \\
D (reaction time) & $\mathbf{0 . 2 1 1 2 5} \pm \mathbf{0 . 0 5 3 5}$ \\
BD interaction & $\mathbf{0 . 1 3 6 2 5} \pm \mathbf{0 . 0 5 3 5}$
\end{tabular}

The lines in bold emphasize the effects that are statistically significant. 
between time of reaction and THA concentration are statistically significant.

THA is a very reactive monomer because its radical is not well stabilized by electronic effects. This would explain the influence of the interaction between THA concentration and reaction time on the functionalization process. On the other hand, the homopolymerization of THA, a parallel undesirable reaction, might be strongly favored upon increasing BPO concentration. The competition between the functionalization reaction and homopolymerization might also explain why the reaction time is statistically relevant for this process. Evidences for the THA homopolymerization were found by adding methanol to the acetone used in the purification process. The maximum amount of precipitate corresponded to approximately $30 \%$ of the initial total mass. Besides the homopolymerization cross-linking reactions also took place yielding at maximum $10 \%$ of the initial total mass. Samples prepared with low BPO level showed no crosslinking. A control experiment was performed in the absence of anhydride. No entangled material was found, indicating that BPO alone does not favor cross-linking. Xylene grafting on polyolefins was not evidenced by FTIR spectra.

Figure 3 shows the response surface built from the central composite design for the THA. The linear model which describes the dependence of DF on the concentration of THA $\left(\mathrm{x}_{1}\right)$ and time of reaction $\left(\mathrm{x}_{2}\right)$ is the polynomial:

$$
\begin{gathered}
\mathrm{DF}=0.31-0.053 \mathrm{x}_{1}+0.105 \mathrm{x}_{2}+0.068 \mathrm{x}_{1} \mathrm{x}_{2} \\
(0.025)(0.027) \quad(0.027) \quad(0.027)
\end{gathered}
$$

where $\mathrm{x}_{1} \mathrm{x}_{2}$ represents the interaction effect and the figures in the brackets represent the standard error coefficients calculated with $95 \%$ of confidence.

The linear model represented in equation (3) showed no lack of fit and the regression was statistically significant. Therefore, this model can be applied for quantitative predictions.

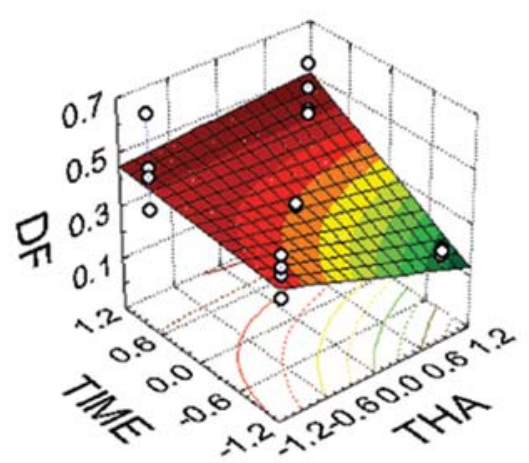

Figure 3. Response surface built from the central composite design $2^{2}$ for the functionalization process with THA.
Regarding the DF values found for MA functionalized samples presented in Table 3, the estimated effects with the corresponding variance for MA were calculated (Table 7). Multiplying the standard deviation related to the effects of 0.036785 by the t-student factor with 8 degrees of freedom and $95 \%$ of confidence yields 0.085 .Therefore, only the BPO concentration (B) and the MA concentration (C) are statistically significant. Based on these results, a central $2^{2}$ composite design with the variables BPO concentration and MA concentration was performed in quadruplicate (Table 8). Considering t-Student factor with 15 degrees of freedom and $95 \%$ of confidence, only effects with values higher than 0.062 are statistically significant. The effects values shown in Table 9 confirm that the variables BPO concentration and MA concentration are statistically significant.

Table 7. Estimated effect with the corresponding standard deviation for the MA functionalized polyolefins. Experimental design $2_{\mathrm{IV}}{ }^{4-1}$

\begin{tabular}{lr}
\hline Mean value & $1.2037 \pm 0.01839$ \\
$\mathrm{~A}$ (type of comonomer) & $-0.0125 \pm 0.03678$ \\
$\mathbf{B}$ (content of BPO) & $\mathbf{0 . 1 7 5 0} \pm \mathbf{0 . 0 3 6 7 8}$ \\
$\mathbf{C}$ (content of anhydride) & $\mathbf{0 . 2 8 0 0} \pm \mathbf{0 . 0 3 6 7 8}$ \\
$\mathrm{D}$ (reaction time) & $-0.0175 \pm 0.03678$ \\
$\mathrm{BC}=\mathrm{AD}$ & $0.0275 \pm 0.03678$ \\
$\mathrm{BD}=\mathrm{AC}$ & $0.0050 \pm 0.03678$ \\
$\mathrm{CD}=\mathrm{AB}$ & $-0.0200 \pm 0.03678$
\end{tabular}

The lines in bold emphasize the effects that are statistically significant.

Table 8. Central composite design $2^{2}$ and data for MA functionalized samples

\begin{tabular}{lcclll}
\hline Run & $\begin{array}{c}\text { BPO } \\
\text { concentration } \\
(\mathrm{g} / \mathrm{L})\end{array}$ & $\begin{array}{c}\text { MA } \\
\text { concentration } \\
(\mathrm{g} / \mathrm{L})\end{array}$ & $\overline{\mathrm{DF}}$ & $\mathrm{s}^{2}$ \\
\hline $\mathrm{a} \mathrm{a}-1 \mathrm{~d}$ & 2 & 8 & 0.99 & 0.004467 \\
$\mathrm{a}-2 \mathrm{~d}$ & 2 & 32 & 1.1375 & 0.007492 \\
$3 \mathrm{a}-3 \mathrm{~d}$ & 8 & 8 & 1.2425 & 0.00029 \\
$4 \mathrm{a}-4 \mathrm{~d}$ & 8 & 32 & 1.445 & 0.003367 \\
Central & 0 & 0 & 1.2975 & 0.001092 \\
\hline
\end{tabular}

Table 9. Estimated effect with the corresponding standard deviation for the MA functionalized polyolefins. Central composite design $2^{2}$

\begin{tabular}{lr}
\hline Mean value & $1.2225 \pm 0.01293$ \\
B (BPO concentration) & $\mathbf{0 . 1 7 5} \pm \mathbf{0 . 0 2 8 9 0 5}$ \\
C (MA concentration) & $\mathbf{0 . 2 8} \pm \mathbf{0 . 0 2 8 9 0 5}$ \\
BC interaction & $0.0275 \pm 0.028905$
\end{tabular}

The lines in bold emphasize the effects that are statistically significant.

Since MA is less reactive than THA because its radical is stabilized by carbonyl group, the MA homopolymerization is less favored. The addition of methanol to the acetone used in the samples purification led to the maximum amount of solids of $15 \%$. Therefore, the weaker competition between the functionalization and homopolymerization reactions might also explain why the reaction time is 
statistically irrelevant for this process. Analyzing the results found for the THA and MA designs, the type of comonomer was in both cases insignificant. It means that increasing the size of lateral groups from two to six carbons has no entropic effect for the functionalization, at least at the level of $10 \%$ of comonomer. Cross-linking sub-products corresponded at maximum to $\sim 5 \%$ of the initial total mass. Samples prepared with low BPO level showed no cross-linking. Xylene grafting on polyolefins was not evidenced by FTIR spectra.

Figure 4 shows the response surface built from the central composite design for the MA. The linear model which describes the dependence of DF on the concentration of $\mathrm{BPO}\left(\mathrm{x}_{1}\right)$ and of MA $\left(\mathrm{x}_{2}\right)$ is:

$$
\mathrm{DF}=1.22+0.09 \mathrm{x}_{1}+0.14 \mathrm{x}_{2}
$$$$
\begin{array}{lll}
(0.013) & (0.014) \quad(0.014)
\end{array}
$$

where the figures in the brackets represent the standard error coefficients calculated with $95 \%$ of confidence.

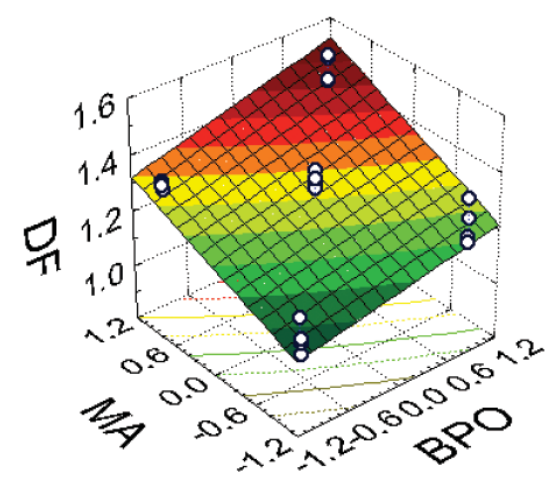

Figure 4. Response surface built from the central composite design $2^{2}$ for the functionalization process with MA.

The linear model represented in equation (4) showed a small lack of fit and the regression was statistically significant. Therefore, in this case, this model can be applied only for semi-quantitative predictions.

The effect of THA or MA grafting on the structure of polyolefins was investigated by means of XRD and DSC. In order to obtain comparable DF values, the functionalization of samples with MA followed a central $2^{2}$ composite design (Table 10), where the polymer concentration was $10 \mathrm{~g} / \mathrm{L}$.

Diffraction peaks and amorphous halo are typical features of semi-crystalline polymers. Polyethylene crystallizes in the all-trans conformation and belongs to the orthorhombic crystal class. The corresponding lattice constants $^{23}$ amounts to $\mathrm{a}=0.742 \mathrm{~nm}, \mathrm{~b}=0.495 \mathrm{~nm}$ and $\mathrm{c}=$ $0.254 \mathrm{~nm}$. Figure 5a shows typical curves of X-ray
Table 10. Central composite design $2^{2}$ and data for MA functionalized samples, using $10 \mathrm{~g} / \mathrm{L}$ of polymer

\begin{tabular}{lccll}
\hline Run & $\begin{array}{c}\text { BPO } \\
\text { concentration } \\
(\mathrm{g} / \mathrm{L})\end{array}$ & $\begin{array}{c}\text { MA } \\
\text { concentration } \\
(\mathrm{g} / \mathrm{L})\end{array}$ & $\overline{\mathrm{DF}}$ & \multicolumn{1}{c}{$\mathrm{s}^{2}$} \\
\hline $1 \mathrm{a}-1 \mathrm{~d}$ & 0.5 & 2 & 0.215 & 0.00045 \\
$2 \mathrm{a}-2 \mathrm{~d}$ & 0.5 & 8 & 0.52 & 0.0008 \\
$3 \mathrm{a}-3 \mathrm{~d}$ & 2 & 2 & 0.28 & 0.0002 \\
$4 \mathrm{a}-4 \mathrm{~d}$ & 2 & 8 & 0.64 & 0.0085 \\
Central & 0 & 0 & 0.46 & 0.0008 \\
\hline
\end{tabular}
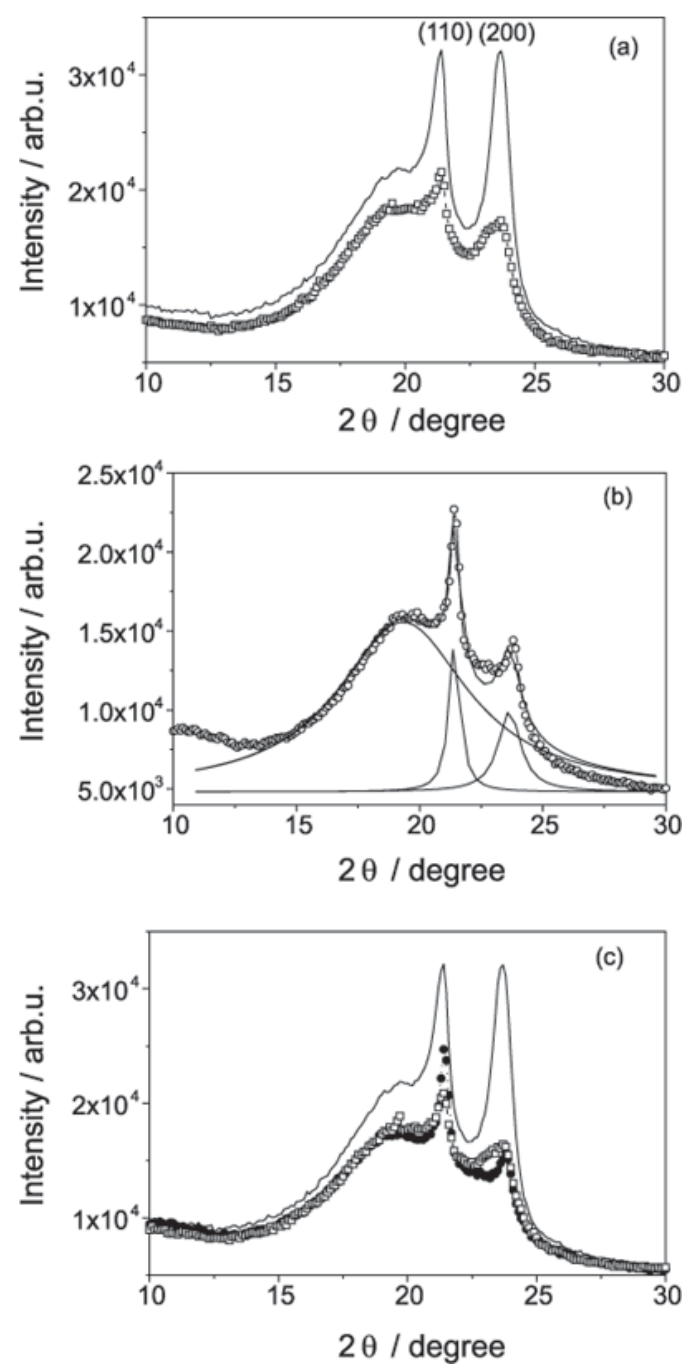

Figure 5. (a) Typical curves of X-ray scattering as a function of scattering angle obtained for the original LLDPE-BUT (solid line) or LLDPE-OCT (square + line) polyolefins, (b) an example of diffractogram decomposition following Lorentz function fits and (c) diffractograms of MA functionalized LLDPE-BUT, DF $=0.54$ (dotted line), THA functionalized LLDPE-BUT, DF $=0.41$ (square + line), and the original LLDPE-BUT sample (solid line).

scattering as a function of scattering angle obtained for the original LLDPE-BUT or LLDPE-OCT polyolefins. The diffraction peaks at $\sim 21.4^{\circ}$ and $\sim 23.6^{\circ}$ correspond to the 
Table 11. Areas corresponding to the diffraction peaks (110) and (200) and to the amorphous halo and peak positions for LLDPE-BUT and LLDPE-OCT samples before and after the functionalization with MA or THA. The area values are resulting from decompositions following Lorentz fits

\begin{tabular}{lcccccc}
\hline Sample & DF & $\begin{array}{c}\text { Area (110) } \\
\text { (arb.u.) }\end{array}$ & $\begin{array}{c}\text { Area (200) } \\
\text { (arb.u.) }\end{array}$ & $\begin{array}{c}\text { Area Amorphous } \\
\text { halo (arb.u.) }\end{array}$ & $\begin{array}{c}\text { Peak position } \\
(110) \\
(\text { degree })\end{array}$ & $\begin{array}{c}\text { Peak position } \\
(200) \\
(\text { degree })\end{array}$ \\
\hline LLDPE-BUT & - & 18162 & 28434 & $1.410^{5}$ & 21.37 & 23.65 \\
LLDPE-OCT & - & 13741 & 16079 & $1.010^{5}$ & 21.35 & 23.54 \\
LLDPE-BUT-THA & 0.41 & 8550 & 9272 & $1.210^{5}$ & 21.42 & 23.65 \\
LLDPE-OCT-THA & 0.07 & 8411 & 13429 & $1.210^{5}$ & 21.38 & 23.51 \\
LLDPE-BUT-MA & 0.54 & 14027 & 12478 & $1.010^{5}$ & 21.33 & 23.54 \\
\hline
\end{tabular}

diffraction planes (110) and (200), respectively, of both original samples LLDPE-BUT and LLDPE-OCT (Table 11). ${ }^{24,25}$ The relative intensities reveal that LLDPE-BUT presents higher crystallinity than LLDPE-OCT. Androsch ${ }^{24}$ attributed this effect to the length of the side-chains on the orthorhombic crystalline phase.

The interplanar spacing $\mathrm{d}_{\mathrm{hk} l}$ was determined by applying Bragg's equation:

$$
d_{h k l}=\frac{\lambda}{2 \sin \theta_{h k l}}
$$

where $\theta_{\mathrm{hk} l}$ is half of the diffraction angle of the (hk $l$ ) atomic plane and $\lambda$ is the wavelength of the $\mathrm{X}$-ray.

The characteristic lattice constants $a$ and $b$ are 0.75 and $0.50 \mathrm{~nm}$, respectively. These values are identical with those reported for poly(ethylene), ${ }^{23}$ indicating that LLDPEBUT and LLDPE-OCT also belong to the orthorhombic crystal class. The determination of constant $c$ could not be accomplished, since reflections with $l \neq 0$ were not observed. The amorphous region is evidenced by the amorphous halo.

All diffractograms were decomposed following Lorentz function fits in order to quantify the area corresponding to the diffraction peaks (110) and (200) and to the amorphous halo, as exemplified in Figure 5b. The insertion of MA or THA in the polyolefin chains led to reduction in the (110) and (200) peak areas in the range of 50 to $70 \%$, as shown in Table 11 and illustrated in Figure 5c. These reductions in the peak areas indicate that the functionalization diminishes the crystallinity, although the lattice constants are not affected by the presence of MA or THA, since there is no change in the (110) and (200) peak positions after the functionalization. Comparing functionalized LLDPEBUT with similar contents of THA $(\mathrm{DF}=0.41)$ and MA $(\mathrm{DF}=0.54)$, the reductions in the peak areas are stronger for the former, probably because it is bulkier than the latter.

The melting temperature of the original and modified samples was determined from the peak temperature observed in the DSC curves. Typical curves obtained for
LLDPE-BUT and LLDPE-OCT and THA functionalized LLDPE-BUT are shown in Figure 6 (the curves for other THA functionalized and MA functionalized polyolefins are available). In the case of THA, the increase in DF decreased the melting temperature up to $4.3^{\circ} \mathrm{C}$, as shown in Table 12. This effect was also observed in the case of MA functionalized samples and corroborates with the reduction in the crystallinity observed by XRD measurements. However, the samples LLDPE-BUT-THA with $\mathrm{DF}=0.41$ presented $\Delta \mathrm{T}_{\mathrm{m}}$ of $4.3^{\circ} \mathrm{C}$, while the samples LLDPE-BUT-MA with $\mathrm{DF}=0.54$ presented $\Delta \mathrm{T}_{\mathrm{m}}$ of $1.4^{\circ} \mathrm{C}$. Despite of the similar DF values, the insertion of a bulkier group, namely THA, seems to perturb the crystalline arrangement in a more effective way, as evidenced by XRD

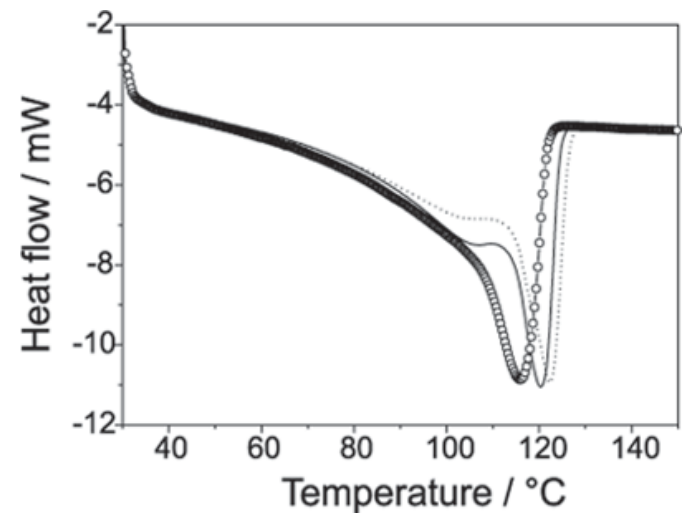

Figure 6. Typical DSC curves obtained for LLDPE-BUT (solid line) and LLDPE-OCT (dotted line) and THA functionalized LLDPEBUT (circle + line).

Table 12. Melt temperature $\left(T_{m}\right)$ and the decrease in $T_{m}\left(\Delta T_{m}\right)$ obtained for LLDPE-BUT and LLDPE-OCT samples before and after the functionalization with MA or THA

\begin{tabular}{lccc}
\hline Sample & $\mathrm{DF}$ & $\mathrm{T}_{\mathrm{m}}\left({ }^{\circ} \mathrm{C}\right)$ & $\Delta \mathrm{T}_{\mathrm{m}}\left({ }^{\circ} \mathrm{C}\right)$ \\
\hline LLDPE-BUT & - & 120.2 & - \\
LLDPE-OCT & - & 122.2 & - \\
LLDPE-OCT-THA & 0.07 & 122.2 & 0 \\
LLDPE-OCT-THA & 0.36 & 121.1 & 1.1 \\
LLDPE-BUT-THA & 0.41 & 115.9 & 4.3 \\
LLDPE-BUT-MA & 0.27 & 119.5 & 0.7 \\
LLDPE-BUT-MA & 0.54 & 118.8 & 1.4 \\
LLDPE-OCT-MA & 0.70 & 118.9 & 3.3 \\
\hline
\end{tabular}


analysis. For modified polyethylene such effects are scarcely reported in the literature. ${ }^{26}$ In the case of polypropylene, functionalization generally leads to an increase in the crystallinity, which is attributed to chain scission and increased degree of order. ${ }^{7,27,28}$

\section{Conclusions}

The reaction time and the interaction between time of reaction and THA concentration influenced the functionalization of LLDPE-BUT and LLDPEOCT with THA. A linear model was proposed to describe quantitatively the dependence of the degree of functionalization on these variables. In the case of MA, a linear model was found, which describes semi-quantitatively the dependence of the degree of functionalization on MA and BPO concentrations. The length of comonomer showed no influence on the grafting process, at least at the studied levels. XRD and DSC analysis showed that THA functionalized polyolefins showed larger changes in the crystalline structure than MA functionalized samples, in comparison to the original polymers. This effect might be explained based on the bulkier structure of THA.

The present study showed that THA might be used as a grafting agent for polyolefins as well as MA. Grafting THA onto LLDPE-BUT and LLDPE-OCT reduced the original crystallinity and melt temperature, what might be advantageous for processing purposes.

\section{Acknowledgements}

The authors are grateful to FAPESP and CNPq for financial support, to Prof. Dr. Roy E. Bruns (IQ-UNICAMP) for helpful discussions about the statistical analysis, to Eng. Ademar Lugão (IPEN, SP) for allowing us to use the DSC equipment, to Eng. Sérgio D. Almeida (Politeno, SP) for supplying the polyolefin samples and to Eduardo A. O. Reis for technical support.

\section{References}

1. http://isi3.newisiknowledge.com; accessed in October 2003.

2. Wu, S.; Polymer Interface and Adhesion, Marcel Dekker: New York, 1982.

3. Zerroukhi, A.; Cincu, C.; Montheard, J. P.; J. Appl. Polym. Sci. 1999, 71, 1447.

4. Zhang, F.; Kabeya, H.; Kitagawa, R.; Hirotsu, T.; Yamashita, M.; Otssuki, T.; Chem. Mater. 1999, 11, 1952.

5. Zhang, F.; Endo, T.; Kitagawa, R.; Kabeya, H.; Hirotsu, T. J.; Mater. Chem. 2000, 10, 2666.
6. Kato, M.; Usuki, A.; Okada, A.; J. Appl. Polym. Sci. 1997, 63, 137.

7. Bettini, S. H. P.; Agnelli, J. A. M.; J. Appl. Polym. Sci. 2002, 85, 2706.

8. Lee, S. Y.; Kim, S. C.; J. Appl. Polym. Sci. 1998, 68, 1245.

9. Yoon, K. H.; Lee, H. W.; Park, O. O.; J. Appl. Polym. Sci. 1998, 70, 389.

10. Liu, N. C.; Baker, W. E.; Russell, K. E.; J. Appl. Polym. Sci. 1990, 41, 2285.

11. Gaylord, N. G.; Mehta, R.; J. Appl. Polym. Sci. 1988, 26, 1189.

12. Gaylord, N.G.; Mehta, R.; Kumar, V.; Tayi, M.; J. Appl. Polym. Sci. 1989, 38, 359.

13. Gaylord, N.G.; Mehta, R.; Mohan, D. R.; Kumar, V.; J. Appl. Polym. Sci. 1992, 44, 1941.

14. Pasaglia, E.; Corsi, L.; Aglietto, M.; Ciardelli, F.; Michelotti, M.; Suffredini, M.; J. Appl. Polym. Sci. 2003, 87, 14.

15. Machado, A.V.; Covas, J. A.; van Duin, M.; Polymer 2001, 42, 3649.

16. Moad, G.; Prog. Polym. Sci. 1999, 24, 81.

17. De Roover, B.; Sclavons, M.; Carlier, V.; Devaux, J.; Legras, R.; Momtaz, A.; J. Appl. Polym. Sci. 1995, 33, 829.

18. Maurano, C. H. F.; Galland, G. B.; Mauler, R. S.; Polímeros: Ciência e Tecnologia 1998, Jul/Set, 79.

19. Heine, W.; Rosenmöller, C. H.; Wenzel, C. B.; de Groot, H. J. M.; Lugtenburg, J.; van Duin, M.; Macromolecules 1996, 29, 1151 .

20. Barra, G. M. O.; Crespo, J. S.; Bertolino, J. R.; Soldi, V.; Pires, A. T. N.; J. Braz. Chem. Soc. 1999, 10, 31.

21. Neto, B. B.; Scarmio, S. I.; Bruns, E. R.; Como Fazer Experimentos, Unicamp: Campinas, 2001.

22. Box, G. E. P.; Hunter, W. G.; Hunter, J. S.; Statistics for Experimenters: An Introduction to Design, Data Analysis and Model building, Wiley: New York, 1978.

23. Elias, H. G.; An Introduction to Polymer Science, $1^{\text {st }}$ ed., VCH: New York, 1997.

24. Androsch, R.; Polymer 2000, 40, 2805.

25. Cser, F.; Hopewell, J. L.; Shanks, R. A.; J. Appl. Polym. Sci. 2001, 81, 340.

26. Pesetski, S. S.; Jurkowski, B.; Makarenko, O. A.; J. Appl. Polym. Sci. 2002, 86, 64.

27. Collar, E. P.; Cofrades, A. G.; Laguna, O.; Areso, S.; Martínez, G. J. M.; Eur. Polym. J. 2000, 36, 2265.

28. Duvall, J.; Selliti, C.; Myers, C.; Hiltner, A.; Baer, E.; J. Appl. Polym. Sci. 1994, 52, 207.

Received: November 3, 2003

Published on the web: June 29, 2004

FAPESP helped in meeting the publication costs of this article. 